\title{
Evaluation of Treatment by Pulsed Electromagnetic Fields in a Rabbit Hyphema Model
}

\author{
Gregor Wollensak ${ }^{a}$ Felix Muchamedjarow ${ }^{a}$ Richard Funk ${ }^{b}$ \\ a Department of Ophthalmology, Universitätsklinikum CGC, and ${ }^{\mathrm{b}}$ Department of Anatomy, \\ Technical University of Dresden, Dresden, Germany
}

\section{Key Words}

Pulsed electromagnetic fields . Histopathological study . Hyphema $\cdot$ Rabbit $\cdot$ Side effects

\begin{abstract}
Purpose: Previous clinical studies have suggested a positive effect of low-frequency pulsed electromagnetic fields (PEMF) on wound healing and inflammation in the eye. We tried to test the value of PEMF treatment in a hyphema animal model with well-defined conditions. Methods: After injection of citrated autologous blood for the production of hyphema, 16 rabbit eyes were treated with 10 or $20 \mathrm{mT}$ for $60 \mathrm{~min}$ on 4 days within the postoperative week. Two control groups with hyphema alone $(n=8)$ and PEMF irradiation without hyphema $(n=4)$ were also included. The rate of resorption was recorded daily. Histopathologic evaluation was performed. Results: The incidence of endothelial cell damage and fibrotic clots was markedly reduced in the 10-mT group while the resorption time of 8 days was identical with the control group. In the 20-mT group, the complication rate and the resorption time was increased versus the control group. Conclusions: The use of PEMF treatment is of some, however, limited value as it did not reduce the resorption time of hyphema but displayed a dose-dependent, beneficial influence on some serious side effects.
\end{abstract}

Future clinical studies with low-dose PEMF irradiation are justified and should determine the optimal dosage and suitable indications of PEMFs as an adjunctive treatment in ocular inflammation or trauma.

Copyright $\odot 2003$ S. Karger AG, Basel

\section{Introduction}

In previous mostly clinical studies, it has been shown that so-called low-frequency pulsed electromagnetic fields (= PEMF) have a beneficial effect in wound healing, resorption of inflammatory edema or bleeds in various organs by stimulating metabolic processes, blood circulation and activating cell proliferation. The exact mechanisms for the biological effects of PEMF are not yet understood. In vitro studies have demonstrated effects of PEMF on ion transport across cell membranes, DNA synthesis, RNA transcription and cell division rate [1]. Widespread use of PEMF is common in orthopedics where successful application of PEMF has been reported for example in the treatment of delayed or non-union bone fractures [2], osteoarthritis or osteoporosis [3]. Moreover, PEMF have been used for the treatment of nerve lesions [4] and in chronic skin wound healing [5] like in venous leg ulcers.

\begin{tabular}{ll}
\hline KARGER & ( ) 2003 S. Karger AG, Basel \\
0030-3755/03/2172-0143\$19.50/0 \\
$\begin{array}{l}\text { E-Mail karger@karger.ch } \\
\text { www.karger.com }\end{array}$ & $\begin{array}{l}\text { Accessible online at: } \\
\text { www.karger.com/oph }\end{array}$
\end{tabular}

PD Dr. Gregor Wollensak

Wildentensteig 4

D-14195 Berlin (Germany)

Tel. +49 30 8264499, Fax +49 351 4584335, E-Mail gwollens@hotmail.com 

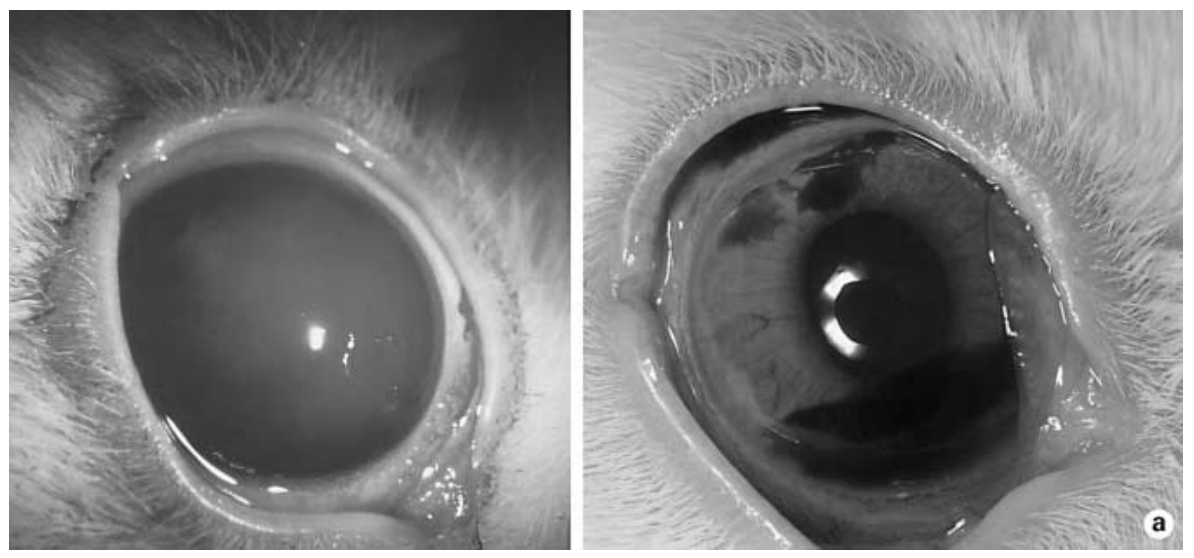

Fig. 1. a Right rabbit eye on the day of injection with total hyphema (left) and with aqueous blood level and 20\% hyphema (right) 5 days after intracameral blood injection (10 mT group). b PEMF generator with anesthetized rabbit under the application head and monitoring unit.

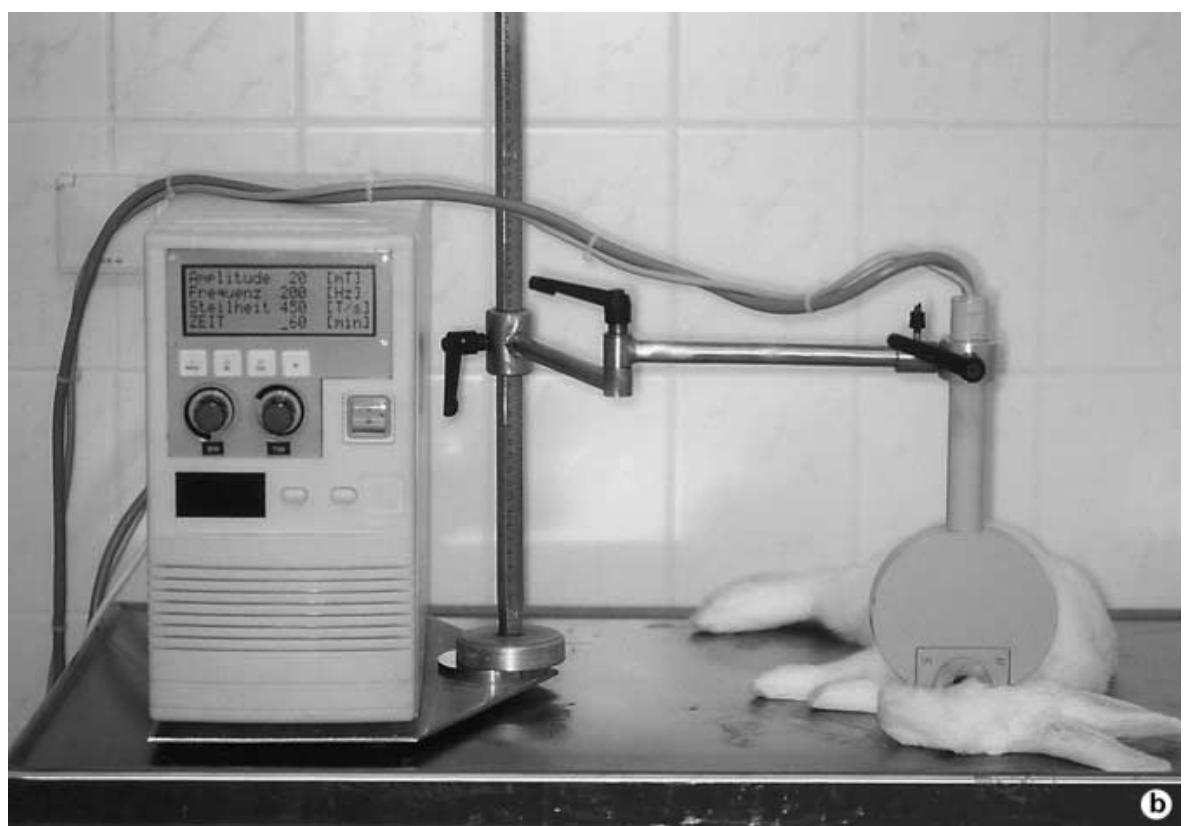

In the eye, the successful use of PEMF has been reported in corneal wound healing [6], dry eye syndrome, acute keratoconus [7], glaucoma [8], endocrine ophthalmopathy [9] and various optic nerve lesions [10]. Most of these studies come from the former Soviet Union and are still controversial or even unknown in Western countries.

Therefore, we have conducted an experimental study to test the effect of PEMF in the eye under well-defined conditions using the hyphema model in rabbits allowing unequivocal quantitative measurements of treatment effects like the rate of hyphema resorption that can be easily assessed because of the transparency of the cornea [11] and evaluation of complications by clinical observation and histopathological examination.

\section{Materials and Methods}

Treatment Groups

28 female New Zealand White rabbits $(2-3 \mathrm{~kg})$ were divided into four groups:

A The low-dose group $(n=8)$ with hyphema was exposed to PEMF $(10 \mathrm{mT}, 50 \mathrm{~Hz}, 50 \mathrm{~T} / \mathrm{s}, 60 \mathrm{~min})$ on days $1,2,3$ and 6 postoperatively.

B The high-dose group $(\mathrm{n}=8)$ with hyphema was exposed to PEMF ( $20 \mathrm{mT}, 200 \mathrm{~Hz}, 450 \mathrm{~T} / \mathrm{s}, 60 \mathrm{~min}$ ) on days 1, 2, 3 and 6 postoperatively.

C A non-irradiated control group $(n=8)$ with hyphema, sham anesthesia and spontaneous resorption to find the spontaneous resorption rate and exclude side effects due to hyphema.

D A control group $(n=4)$ without hyphema but high-dose PEMF treatment $(20 \mathrm{mT}, 200 \mathrm{~Hz}, 450 \mathrm{~T} / \mathrm{s}, 60 \mathrm{~min})$ on days $1,2,3$ and 6 postoperatively to exclude side effects due to irradiation alone. 


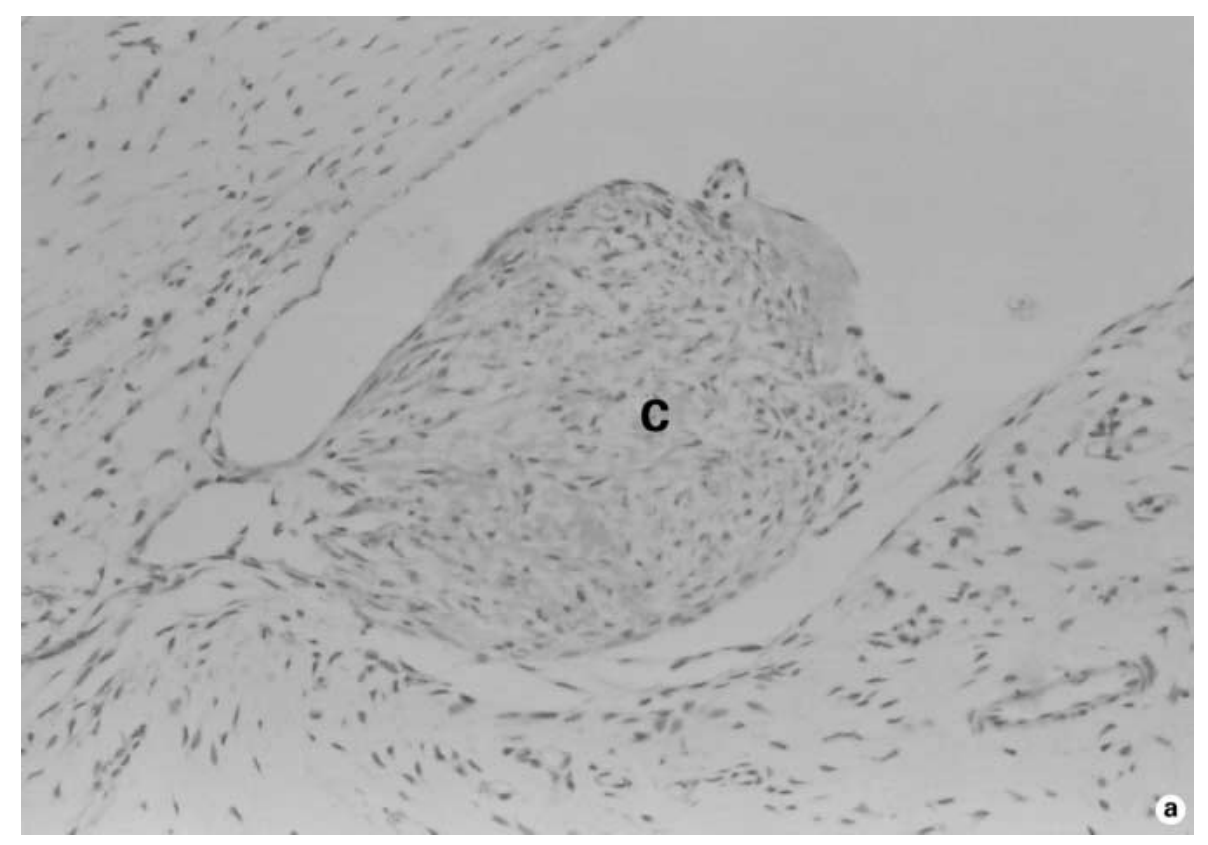

Fig. 2. a Chamber angle with fibrotic blood clot $(=$ C) after $20 \mathrm{mT}$ treatment. HE. $\times 400$. b High-power view of same eye showing degenerated endothelial cells with vacuoles (arrow). HE. $\times 1,000$ (oil immersion).

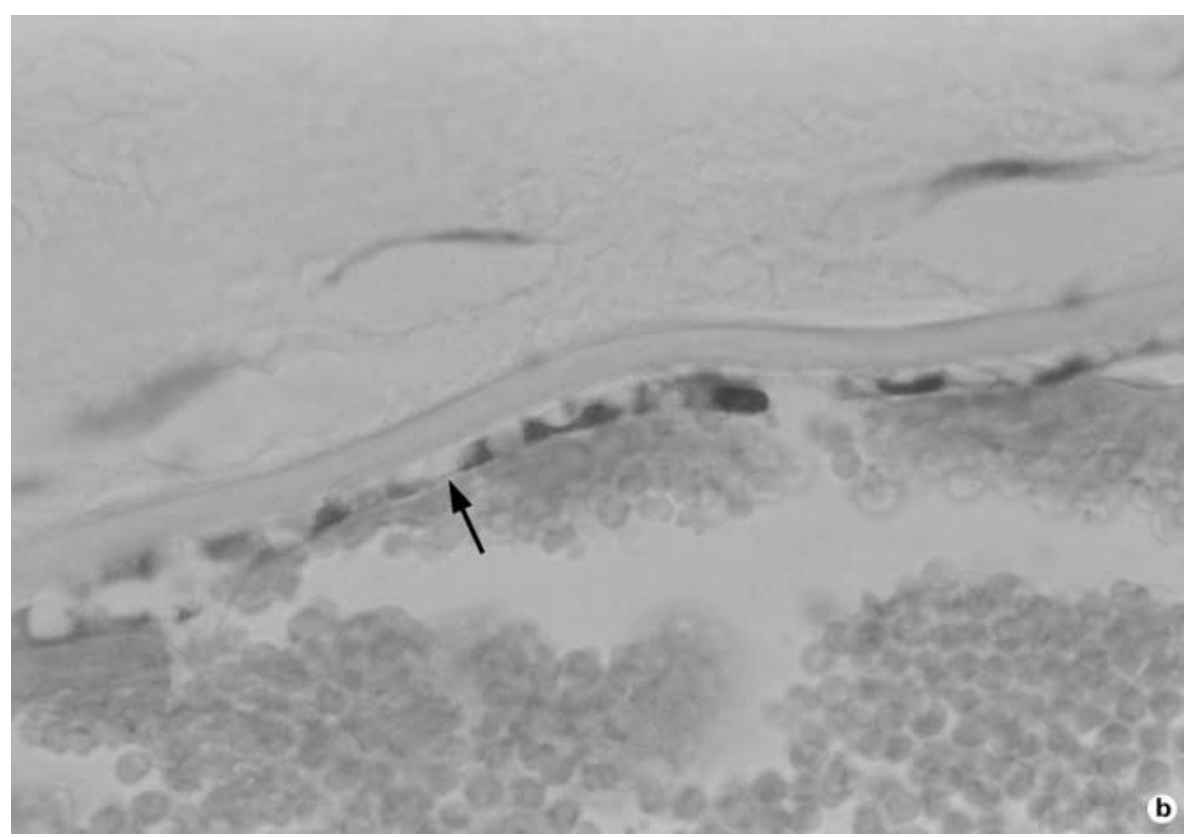

\section{Experimental Hyphema}

For premedication, $1.5 \mathrm{ml}$ ketamine hydrochloride $10 \%$ and $0.5 \mathrm{ml}$ xylazine hydrochloride were given subcutaneously. Anesthesia was achieved with subcutaneous injection of a mixture of diazepam and atropine. Whole blood was drawn from the ear vein using a $1-\mathrm{ml}$ tuberculin syringe containing $0.05 \mathrm{ml}$ of $3.8 \%$ sodium citrate. After instillation of $0.5 \%$ proparacaine hydrochloride onto the cornea, $300 \mu \mathrm{l}$ of aqueous was removed by an injection needle at the 11 o'clock position and the equivalent of about $300 \mu \mathrm{l}$ citrated whole blood was injected instead. No suturing of the injection site was necessary. Postoperatively, antibiotic ointment was applied. The rabbits were checked the next day and only the eyes with at least $55-60 \%$ of hyphema were utilized for the experiment. As the citrated blood gravitated inferiorly with a horizontal aqueous-blood fluid level, the hyphema volume could be estimated as a percentage of the anterior chamber volume (fig. 1a) sometimes supported by transillumination using a pen light. A rough estimation of increased intraocular pressure was made by palpation because tonometry could not be used due to corneal edema. The animals were sacrificed using an overdose of trepanal intravenously when the residual hyphema volume was equal to $5 \%$ of the anterior chamber volume. The animals were handled according to international ethical standards. 


\begin{tabular}{llcl}
\hline Complications & Hyphema alone & $10 \mathrm{mT}+$ hyphema & $20 \mathrm{mT}+$ hyphema \\
\hline Endothelial vacuoles & 87.5 & $60 \Downarrow$ & 85.7 \\
Fibrotic clots & 12.5 & $0 \Downarrow$ & $32.6 \Uparrow$ \\
Corneal edema & 37.5 & 40 & 42.9 \\
Glaucoma & 25 & 20 & 22.2 \\
Corneal neovascularization & 37.5 & 40 & $71.4 \Uparrow$ \\
Iron deposition & 75 & 80 & $100 \Uparrow$ \\
Retroc. membrane & 25 & 20 & 28.8 \\
\hline
\end{tabular}

No complications were observed in the group with irradiation alone.

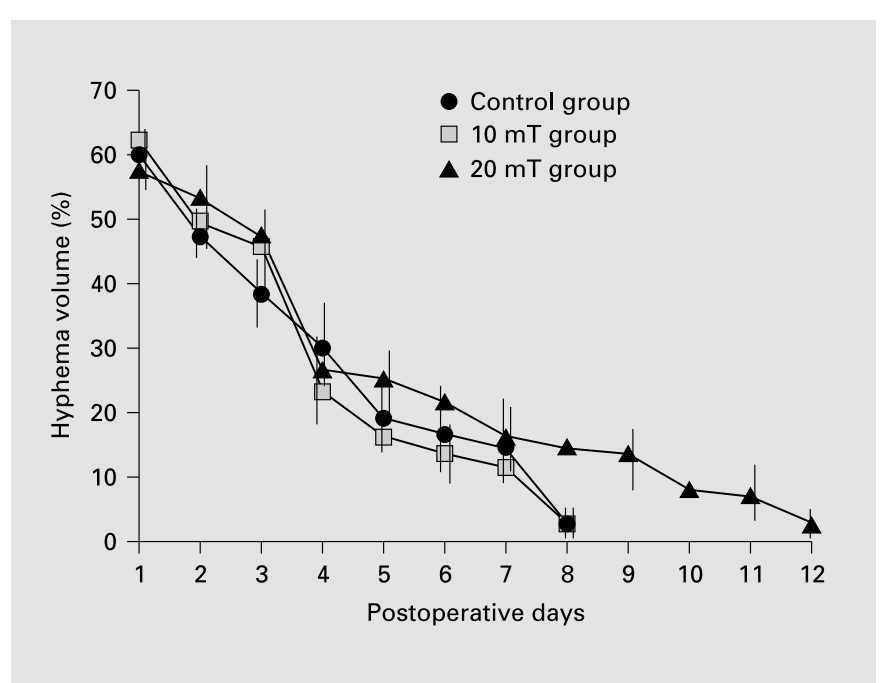

Fig. 3. Resorption rate over time. $x$-axis $=$ Percentage of hyphema volume remaining in anterior chamber $($ mean $\pm S D)$. y-axis $=$ Time after treatment in days.

\section{PEMF Treatment}

For each treatment the rabbits had to be anesthetized. The apparatus used (Schüller-Magnetik, Dortmund, Germany) was especially designed containing a $1.8 \times 28 \mathrm{~cm}$ ring-shaped solenoid electromagnet with a 2-cm open gap for the rabbit eye (fig. 1b). Using a separate monitoring unit, magnetic field parameters like amplitude, pulse frequency, impulse steepness and treatment time could be regulated and monitored (fig. 1b). The cornea was protected with gel during the irradiation.

\section{Histological Evaluation of Complications}

The eyes were enucleated and fixed in $4 \%$ neutral-buffered formalin. The fixed globes were cut in half in a line traversing vertically the residual hyphema and embedded in paraffin. For each case, five $4-\mu \mathrm{m}$-thick paraffin sections were stained with hematoxylin-eosin and Prussian blue. Histopathologic evaluation was performed at various magnifications using a Zeiss axiomat light microscope (fig. 2).

\section{Results}

\section{Average Time of Hyphema Resorption}

The average time of resorption (fig. 3) was $7.75 \pm 1.75$ days in the untreated hyphema group, $8.29 \pm 1.98$ days in the $10-\mathrm{mT}$ group, and $12.43 \pm 4.43$ days in the $20-\mathrm{mT}$ group. Using analysis of variance (ANOVA) a significance level of 0.04 was calculated. Student's $t$ test showed a significant difference in the resorption time between the hyphema control group and the $20-\mathrm{mT}$ group $(\mathrm{p}=0.016)$ and between the 10- and 20-mT groups $(\mathrm{p}=0.043)$. There was no statistically significant difference between the control and the $10-\mathrm{mT}$ groups $(\mathrm{p}=0.587)$.

\section{Complications and Histology}

Remarkably, the incidence of degenerated endothelial cells with vacuoles and fibrotic transformation of blood clots was lower in the 10-mT group vs. the control group. In the 20-mT group, the incidence of corneal neovascularization, iron deposition and fibrotic clots was higher vs. the hyphema group (table 1; fig. 2a, b). Iron deposition was found preferably in the trabecular meshwork, retrocorneal membranes and in remnants of the hyphema. No hematocornea was observed. The lens and retina were unremarkable. There were no side effects in the animals treated only with $20 \mathrm{mT}$ without hyphema.

\section{Discussion}

Our experiments have demonstrated a moderate value of PEMF treatment in the eye. The complication rate was lower in the low-dose group with respect to the frequency of degenerated endothelial cells with vacuoles and of fibrotic clots while the rate of blood resorption of about 8 days was the same in both the low-dose and the control group and is in the time range of previous reports [11,12]. 
In the 20-mT group, the complication rate was higher as for corneal neovascularization, iron deposition and clot fibrosis probably due to the prolonged resorption time which was significantly delayed to about 12 days suggesting a dose-dependent effect when compared with the 10$\mathrm{mT}$ group.

The histological changes observed are important for the risk of the development of the most severe complications of hyphema because hematocornea occurs preferably if either the IOP is increased or endothelial degeneration is present and secondary glaucoma is mostly due to angle closure by fibrotic clots with anterior synechias [12]. In our study, hematocornea itself was not found probably due to the relatively rapid drainage of the bulk of the erythrocytes via the trabecular meshwork and episcleral veins [13] because of the paucity of fibrin formation due to anticoagulation [14]. Others were able to produce hematocornea in rabbits maintaining total hyphema by repeated injections for a time interval of at least 5 days [15].

Both the results for the resorption time and the complication rate point out the importance of the optimal dosage of PEMF being applied and demonstrate that with too strong a dosage even harmful effects might occur. In the literature, a wide range of different doses has been reported. A typical dosage for a therapeutic application in ophthalmology is $9 \mathrm{mT}, 50 \mathrm{~Hz}, 20 \mathrm{~T} / \mathrm{s}, 7 \times 10 \mathrm{~min}$ [8] as has been used in the low-dose group. In other fields, only $0.3 \mathrm{mT}$ with $2 \mathrm{~Hz}$ has been applied for nerve lesions [4] or high doses like $20 \mathrm{mT}$ with $50 \mathrm{~Hz}$ for skin wounds [5].

In conclusion, we think that our experiments have shown a limited but significant value of PEMF treatment in eye trauma and we think that PEMF treatment is well worth being tested as an adjunct treatment in ocular trauma or inflammation in clinical trials. However, future clinical and experimental studies must cautiously determine the optimal dosage, establish suitable clinical indications like vitreous hemorrhage, uveitis, optic neuritis, etc. and exclude long-term side effects like cataract formation or disturbances of the blood-retina barrier.

\section{Acknowledgement}

The authors would like to thank cordially Prof. Josef Wollensak for continuous support in the study.

\section{References}

1 Dihel LE, Smith-Sonneborn J, Russell Middaugh $\mathrm{C}$ : Effects of extremely low frequency electromagnetic field on the cell division rate and plasma membrane of Paramecium tetraurelia. Bioelectromagnetics 1985;6:61-71.

2 Gossling HR, Bernstein RA, Abbott J: Treatment of ununited tibial fractures: A comparison of surgery and pulsed electromagnetic fields (PEMF). Orthopedics 1992;15:711-719.

3 Rubin CT, McLeod KJ, Lanyon LE: Prevention of osteoporosis by pulsed electromagnetic fields. J Bone Joint Surg 1989;71:411417.

4 Walker JL, Evans JM, Resig P, Guarnieri S, Meade P, Sisken BS: Enhancement of functional recovery following a crush lesion to the rat sciatic nerve by exposure to pulsed electromagnetic fields. Exp Neurol 1994;125:302-305.

5 Patino O, Grana D, Bolgiani A, Prezzavento G, Mino J, Merlo A, Benaim F: Pulsed electromagnetic fields in experimental wound healing in rats. J Burn Care Rehabil 1996;17:528-531.
6 McCabe CF, McInerney M, Head S, Bartnovsky M, Wikswo JP, Wang MX: Pulsed electromagnetic field therapy increases the rate of corneal epithelial healing. Invest Ophthalmol Vis Sci 1999;S92:492.

7 Vainstein ES, Kivaev AA, Bebich GA, Zobina LV, Abugova TD: The use of variable magnetic field in the treatment of acute keratoconus. Vestnik Oftalmol 1984;6:44-46.

8 Tsiselsky YV, Kashintseva LT, Skrinnik AV: The influence of pulsed electromagnetic field on the hemodynamics of a glaucomatous eye. Oftalmologicheski J 1990;343:154-157.

9 Jankauskiene AU, Paunksnis A, Bluziene A, Saulgozis J: The effect of pulsed electromagnetic field on patients with endocrine ophthalmopathy. Eur J Ophthalmol 1998;8:253-257.
10 Zobina LV, Orlovskaya LS, Sabayeva GF, Konde LA, Yakovlev AA: Magnetotherapy efficacy in optic nerve atrophy: Preliminary results. Vestnik Oftalmol 1990;106:54-57.

11 Lambrou FH, Snyder RW, Williams GA: Use of tissue plasminogen activator in experimental hyphema. Arch Ophthalmol 1987;105:995997.

12 Walton W, Von Hagen S, Grigorian R, Zarbin M: Management of traumatic hyphema. Surv Ophthalmol 2000;47:297-334.

13 Horven I: A radioautographic study of erythrocyte resorption from the anterior chamber of rabbit eyes. Acta Ophthalmol 1964;42:592599.

14 Milthaler C, Fitz-Gerald CA, Files MA, Binder RF: Anticoagulation and the resorption of hyphemas. Am J Ophthalmol 1965;60:106-108.

15 Gottsch JD, Messmer EP, McNair DS, Font RL: Corneal blood staining: An animal model. Ophthalmology 1986;93:797-802. 